\section{Trabajo e historicidad en la teología de Marie Dominique Chenu*}

\section{Dumar Iván Espinosa Molina**}

RECIBIDO: 20-04-16. APROBADO: 13-09-16

Resumen: La historia, elemento fundamental del cristianismo por la dinámica misma de la encarnación, fue relegada a un segundo plano por la teología abstracta de la neoescolástica. Contrariamente a tal teología, el padre MarieDominique Chenu, O. P. (1895-1990) atiende al dato revelado y al nuevo contexto social en la predicación del Evangelio. Su teología crece en la tradición de la Iglesia al tiempo que es consciente de las problemáticas que aquejan a la sociedad industrializada. El artículo propone el concepto de "función concienciadora de la historicidad en la teología" como clave interpretativa de las investigaciones medievales y contemporáneas de Chenu.

Palabras Clave: Marie-Dominique Chenu, teología del trabajo, historicidad, conciencia, alienación, encarnación, tradición.

\section{Work and Historicity in Marie Dominique Chenu's Theology}

AвSTRACT: History, a fundamental element of Christianity because of the dynamics of incarnation, was relegated to a second place by the abstract Theology of Neoscholasticism. Contrary to such Theology, Father Marie-Dominique Chenu, O. P. (1895-1990), attends to the revealed fact and to the new social context in the preaching of the Gospel. His Theology grows in the Church's tradition while being aware of the problems that afflict the industrialized society. The article proposes the concept of "conscientious function of historicity in Theology" as an interpretive key to Chenu's medieval and contemporary research.

Key Words: Marie-Dominique Chenu, Works Theology, Historicity, Consciousness, Alienation, Incarnation, Tradition.

\section{PARA CITAR ESTE ARTÍCULO:}

Espinosa Molina, Dumar Iván. “Trabajo e historicidad en la teología de Marie Dominique Chenu". Theologica Xaveriana 183 (2017): 63-83. https://doi. org/10.11144/javeriana.tx67-183.thtmdc

* Artículo de reflexión que plantea la función concienciadora de la historicidad como hilo conductor de la obra del padre Marie-Dominique Chenu, O. P., experto medievalista y teólogo de las realidades terrenas contemporáneas, quien influyó en el Concilio Vaticano II.

** Doctor en Teología, Pontificia Universidad Bolivariana, Medellín; Maestría en Teología Patrística e Historia de la Teología, Universidad Gregoriana, Roma. Catedrático de la Universidad de Cundinamarca y docente de Educación Religiosa Escolar en Facatativá, Colombia. ORCID: 0000-0002-3001-8100. Correo electrónico: dumarespinosa@hotmail.com 


\section{Conciencia de la historicidad}

La terminología clásica distingue dos funciones en la teología: la positiva, que reporta el dato revelado, la tradición y el magisterio de la Iglesia, y la función especulativa, que argumenta a partir de ese dato y de las problemáticas contemporáneas a los autores a lo largo de la historia. Sin embargo, no siempre se desarrollaron equilibradamente las dos funciones de la teología. En algunos momentos de la historia se dio mayor importancia a uno de los dos aspectos y se redujo la teología a una serie de principios y normas o a reflexiones muy personales de algunos teólogos que llegaron a poner en tela de juicio la doctrina.

Un ejemplo del desequilibrio en las funciones es el olvido de la historicidad por parte de cierta teología, más preocupada por la conservación de un orden preestablecido que por el diálogo con los hombres y las mujeres de cada época, que contribuyó por su escape del mundo al nacimiento de ateísmos y a la pérdida del sentido religioso. Lo describe Chenu con una paradoja:

La toma de conciencia de la historicidad del hombre, en el curso de los dos últimos siglos, que hubiera debido aparecer como cosa homogénea a una religión que se remite a la venida de Dios en la historia, ha entrado en juego, de hecho, contra una institución eclesiástica totalmente preocupada por el sostenimiento del orden, en una visión inmovilista de la verdad, de la moral, del comportamiento social, del depósito de la fe. ${ }^{1}$

Lo anterior causó la separación de lo religioso y lo profano en ámbito católico:

El "más allá" de la historia, los "novísimos", hacían caduco y digno de desprecio el desenvolvimiento de la misma; el espíritu escapaba al materialismo del tiempo; el único progreso auténtico se situaba en la "vida interior"; la verdad era definida y calificada por la inmutabilidad; la historificación, sobre todo la historificación deliberada, constituía un síntoma de descristianización. Por todas estas razones, la Iglesia condenaba no solamente las revoluciones, sino la evolución. Frente a lo cual, el ateísmo, bajo todas sus formas, se presenta como el liberador de todos los valores terrestres, en la realidad histórica del hombre, en la verdad humana de la historia. ${ }^{2}$

Contrariamente a lo planteado por tal teología abstracta, Chenu propone retornar al hombre concreto, en un espacio y un tiempo determinados, en el que el trabajo constituya una manifestación de su historicidad y un camino para recuperar el verdadero sentido de la historia.

\footnotetext{
${ }^{1}$ Chenu, "Historicidad e inmutabilidad del ser cristiano", 151.

${ }^{2}$ Ibíd., 151-152.
} 
...el progreso de la civilización científica e industrial -"la civilización del trabajo"- proporciona al hombre la esperanza y el medio de construir el universo. La toma de conciencia de este poder demiúrgico obliga al hombre a que llegue a tomar conciencia de sí mismo y, por ello, a procurarse el justo equilibrio en su sentimiento de criatura. ${ }^{3}$

De esta forma, la teología del trabajo supera la brecha entre realidad histórica y sentimiento religioso.

La teología de Chenu procede, entonces, de una columna vertebral que es el concepto de toma de conciencia de la historicidad, el cual se podría traducir como la función concienciadora de la historicidad en la teología. En efecto, el concepto de "toma de conciencia", en Chenu, es recurrente y polivalente porque lo usa al afrontar diversos temas teológicos, filosóficos, e históricos. En este sentido, la toma de conciencia es le trait d'union de la teología del Chenu medievalista y del Chenu de la teología del trabajón.

Se presenta a continuación una síntesis de la obra de $\mathrm{Chenu}^{5}$, especialmente de su teología del trabajo, desde cuatro enfoques que recogen su pensamiento en más de cincuenta años de investigación y en los que es posible evidenciar la "función concienciadora de la historicidad" en su teología:

- $\quad$ El primer enfoque, sociológico-filosófico, trae a colación, para la reflexión teológica, aportes de teóricos importantes de la antropología contemporánea según los cuales el trabajo se convierte, con la Revolución industrial, en instrumento de alienación.

- $\quad$ El segundo enfoque, bíblico y teológico, indaga en la Escritura y en la tradición la conciencia genuina del trabajo como encarnación y cooperación del hombre y la mujer en la creación.

- $\quad$ Un tercer enfoque, denominado retrospectivo, reporta las investigaciones de Chenu sobre el despertar del sentido de la historia en teólogos del siglo XII.

${ }^{3}$ Ibíd., 156.

${ }^{4}$ Una biografía completa del autor se encuentra en el artículo de Biffi, "Marie-Dominique Chenu (1895-1990)", escrito en lengua italiana por Inos Biffi, conocedor de su persona y editor de sus obras.

${ }^{5}$ En los siguientes documentos se pueden encontrar bibliografías de la obra de Chenu que sirvieron de insumo en el proceso heurístico de la presente investigación: Duval, "Bibliographie du P. Marie-Dominique Chenu (1921-1965)”, 9-29; Gallo, La concepción de la salvación y sus presupuestos en Marie-Dominique Chenu, 13-16; Mazzarello, "Gli scritti del p. Marie-Dominique Chenu 1963-1979”, 855-866 ; Chenu, La fe en la inteligencia. Bibliografía general de padre Chenu 1922-1965, 369-389. Puede verse también el análisis cronológico de las obras medievalistas de Chenu en Schmitt, "L'œuvre de médiéviste du père Chenu", 397-398. 
- Finalmente, un cuarto enfoque, prospectivo, indaga la toma de conciencia de la historicidad en el quehacer teológico contemporáneo: desde la controversia modernista de inicios del siglo XX, pasando por los estudios históricos de Le Saulchoir, hasta la reivindicación de la historia en el Concilio Vaticano II.

\section{Toma de conciencia del trabajo como alienación en la sociedad industrial}

La conciencia de la historicidad lleva a Marie-Dominique Chenu a reconocer la problemática del mundo obrero en la posguerra, sumido en la pobreza y tentado por el ateísmo. De este modo, el contexto sociocultural, con sus entramados históricos, entra en su obra. De hecho, la conciencia histórica en teología no se refiere solo a eventos bíblicos del pasado, sino que es una característica esencial del cristianismo.

En el análisis del trabajo y de la situación actual de los trabajadores, luego de la Revolución industrial, se sirve Chenu de un grupo de autores, algunos muy comentados en la primera mitad del siglo XX en el ámbito católico, como Jacques Maritain, Emmanuel Mounier, Jean Lacroix y Gabriel Marcel. Estos autores corresponden a la llamada filosofía personalista.

Del personalismo aprehende Chenu que la socialización es el resultado cada vez más elaborado del desarrollo integral del género humano. Se trata de la integración de todos como responsables del destino común de la humanidad hacia la fraternidad y la justicia. A este respecto, cita a Maritain:

...el fenómeno más importante que se produjo en el siglo XIX es la toma de conciencia de sí misma efectuada por la persona obrera y por la comunidad obrera. Esta toma de conciencia significa el camino hacia la libertad y la personalidad, tomadas en su realidad interior y en su expresión social, de una comunidad de personas. ${ }^{6}$

Por otra parte, y para efectos del análisis de la situación actual del trabajo, Chenu cita a Marx, fundamentalmente en su obra Manuscritos filosóficos de Paris (1844), y en la "Carta a Hartmann"; menciona también la obra conjunta de Marx y Engels, Escritos filosóficos, y cita obras de sociólogos y de filósofos marxistas como Garaudy y Friedmann. Todos estos autores constituyen la base filosófica personalista y marxista del libro Hacia una teología del trabajo (1955), que denuncia los excesos de la Revolución industrial.

\footnotetext{
${ }^{6}$ Maritain, Les droits de l'homme et la loi naturelle, 94, que es citado por Chenu en El Evangelio en el tiempo, 146.
} 
En efecto, con la introducción de la máquina a vapor, en el siglo XVIII, en Europa inicia la denominada Revolución industrial, que representa la transformación de la economía feudal y del comercio nacido luego del descubrimiento del nuevo mundo. Se pasa del trabajo artesanal basado en la herramienta al trabajo industrial. Con la aparición de la máquina, los nuevos procesos de producción significan ahorro de tiempo y de mano de obra.

A pesar del progreso material que supone la Revolución industrial, el trabajo, en este mismo contexto, se convierte en medio de alienación. Marx es quien conceptualiza dicha conciencia de la alienación moderna, y considera que la consecuencia más nefasta de la industrialización es la creación del proletariado, una nueva clase social de pobres alienados por su trabajo, deshumanizada y arrancada de su entorno familiar, que sobrevive en condiciones infrahumanas?

El ser humano, dominado por los automatismos de la máquina, es reducido, cada vez más, a ser una pequeña e insignificante pieza en el engranaje de la producción industrial. "El trabajo se halla pues en un estado de subversión que deshumaniza: la emancipación del trabajo señala el retorno al hombre. Tal es el humanismo de Marx"».

El diagnóstico de la esclavitud del hombre contemporáneo, así como la "revelación del homo oeconomicus" realizada por el marxismo muestran que los adelantos técnicos no representan siempre progreso espiritual. La revolución causada por el descubrimiento del homo oeconomicus, en Marx, consiste fundamentalmente en la toma de conciencia del valor social e histórico del trabajo, por el que la comunidad humana llega a la edad adulta en el reconocimiento de su potencia comunitaria.

No obstante la alienación causada por el maquinismo, Chenu descubre las dimensiones de la individualidad y de la socialización en el trabajo. Este, a pesar de la inclusión de la máquina durante la Revolución industrial, tiene el poder de crear socialización y despertar la conciencia individual y colectiva.

${ }^{7}$ Chenu Hacia una teología del trabajo, 15. El planteamiento de Marx se suma a las denuncias que condujeron a la teorización de la llamada cuestión social por la explotación a que eran sometidos los trabajadores en las fábricas durante la Revolución industrial. De acuerdo con Guido Gerosa, en este contexto, "la Rerum novarum de León XIII (1891) llevó a encuadrar las masas obreras en una acción católica, fuerza completamente nueva en Europa. A la Internacional socialista de Marx se ha contrapuesto una idéntica fuerza cristiana. Las energías suscitadas por este acto de papa Pecci fueron infinitas. Según Pío XI, "la encíclica de 1891 ha sido el fundamento de toda la actividad cristiana en materia social, aunque llegó con treinta años de retardo y el socialismo se había apoderado de las masas" (I Papi, 1974, 28). En efecto, gobiernos europeos establecieron con anterioridad el asistencialismo para mejorar la situación de los obreros. En la actualidad, el francés Pierre Rosanvallon -en La nouvelle question sociale. Repenser l'Etat-providence- plantea una nueva cuestión social dado que la necesidad de los rezagados en la sociedad es ahora la integración y la solidaridad para la refundación de los derechos sociales.

${ }^{8}$ Chenu Hacia una teología del trabajo, 55. 
En nuestro tiempo, el trabajo ya no tiene tan solo la finalidad de hacernos ganar el pan; crea en cierto modo energía social puesta inmediatamente al servicio de la humanidad entera. En su miseria tiene el obrero, a través de sus amargas reivindicaciones, una conciencia confusa de esta eficacia admirable?.

En esta conciencia, la historia es fundamental porque señala -en el espacio y en el tiempo- el avance progresivo de la comunidad humana hacia su plena realización. Sobre este aspecto, la obra de Marx muestra a Chenu el necesario anclaje histórico que cualquier discurso significativo debe tener también en la teología. La lectura de los Cuadernos de Paris permite a Chenu un acercamiento al hombre contemporáneo desde la historicidad en la concreción de las circunstancias particulares de la enajenación causada por la Revolución industrial.

Chenu desarrolla así el concepto de alienación al tomar conciencia de la deshumanización a que son sometidos los obreros en las fábricas. En la práctica, el trabajo, que debiera ser "creador de libertad", se convierte en instrumento de alienación: “...si el trabajador tiene que 'vender' su trabajo para vivir, podemos estar seguros $a$ priori de que será esclavo de su trabajo, que su trabajo estará 'alienado”. Y se pregunta Chenu: ¿En qué consiste, pues, la alienación del trabajo? Y responde con una tesis de Karl Marx de Cuadernos de Paris:

En el hecho de que el trabajo es algo exterior al trabajador, es decir, que no pertenece a su esencia, que, por consiguiente, él no se afirma en su trabajo, sino que se niega, no se siente contento sino desgraciado [...] si el hombre está "desposeído", "despojado" de su trabajo, este se halla verdaderamente desnaturalizado. Y se convierte así en el lugar de la explotación del hombre por el hombre, incluidos pueblos enteros. ${ }^{10}$

Después de Marx, el concepto de alienación se convierte en terreno común de reflexión filosófica y teológica. Pablo VI lo menciona en relación con la secularización provocada por el espejismo del progreso ilimitado prometido por la Revolución industrial, y afirma en 1964:

¿Se trata acaso de que no se comprendió a tiempo la transformación psicológica y social que iba a producir el paso del empleo de útiles humildes y primitivos para aliviar la fatiga del hombre al empleo de la máquina con sus nuevas y potentísimas energías? ¿No se entrevió que estaba naciendo una fabulosa esperanza en el reino de la tierra capaz de oscurecer y sustituir la esperanza del reino de los cielos? No se cayó en la cuenta de que la nueva forma de trabajo iba a despertar en el trabajador la conciencia de su alienación, es decir, que él no trabaja para sí mismo sino para otros, con instrumentos no propios sino

\footnotetext{
${ }^{9}$ Ibíd., 20-21.

${ }^{10}$ Ídem, "La teología del trabajo frente al ateísmo", 303-304. Chenu cita a Marx, Cuadernos de Paris. (Notas de lectura de 1844).
} 
de otros, no en solitario sino con otros y que iba a nacer en su ánimo el ansia de una redención económica y temporal que no le dejaba ya apreciar la redención moral y espiritual ofrecida por la fe en Cristo, que no es contraria de aquella sino su fundamento y coronación. ${ }^{11}$

Solo la conciencia, al tomar distancia de su obra, puede rescatar al hombre de la alienación del trabajo. La toma de conciencia es seguramente la característica más humana del hombre que le permite elevarse sobre sí mismo y dominar la creación al ser conciencia del Creador en el mundo.

Por su parte, el cristianismo aporta una visión optimista del trabajo, aunque en algunos ambientes solo se consideraba su función purgante como sanción por la culpa original. De acuerdo con Chenu, los cristianos también denunciaron los excesos de la codicia humana en la sociedad, pero no alcanzaron el grado de conceptualización logrado por Marx en su "revelación" de la sociedad y la historia a partir del trabajo industrializado. No se debe perder de vista la consideración fundamental en Chenu, del aporte de otras ciencias, en la concienciación del hombre y su trabajo.

Se plantean así dos formas de hacer teología: una encarnada y otra alienada. Contrariamente a la teología atenta a la historia y a los descubrimientos de otras ciencias, la teología alienada es una tentación para el teólogo de todos los tiempos, desconocedor de la encarnación y de la historia. Es un tipo de teología que se contrapone a la teología encarnada, que siempre tiene algo que decir a los hombres de su época.

\section{Toma de conciencia del trabajo como encarnación}

Sin perder de vista la lectura antropológica proporcionada por Marx en sus Manuscritos económico-filosóficos de 1844, y por los personalistas, debido a que "las coyunturas temporales en que se encuentra el hombre no son algo accidental sino la condición misma de su existencia; a que el tiempo no es algo ocasional en la vida del espíritu" ${ }^{12}$, Chenu se acerca al dato escriturístico sobre el trabajo. Una toma de conciencia social e histórica en el método bíblico le permite acercarse al dato revelado en búsqueda de las grandes líneas teológicas, más allá de la diversidad y disparidad de los textos singulares ${ }^{13}$.

${ }^{11}$ Pablo VI, "Alocución del 1o. de mayo de 1964".

${ }^{12}$ Chenu, "Les signes des temps", 29.

${ }^{13}$ En este sentido, se pueden encontrar textos contradictorios en la Escritura que deben interpretarse a la luz de las grandes líneas teológicas, más allá de los textos individuales como los que en el Nuevo Testamento son permisivos con la esclavitud. Ejemplos: Ef 6,5; 1P 2,18. 
El teólogo dominico, al escrutar la Escritura y la tradición de la Iglesia, toma conciencia de la ambivalencia del trabajo como alienación o como encarnación. Es encarnado cuando significa cooperación del ser humano en la creación continua del mundo obrada por Dios. Es alienante cuando sirve de instrumento a la esclavitud del hombre por el hombre.

El primer capítulo del Génesis es el texto más significativo para la teología del trabajo. Comenta Chenu que todo ese capítulo tiene una función simbólica. De este modo, el texto del Génesis no relata episodios prehistóricos sino acontecimientos que todavía se están desarrollando. El autor invita a ver el Génesis en los siguientes términos:

...no como un episodio inicial y prehistórico (trascendencia puramente estática de Dios, naturaleza prefabricada e inmutable), sino dentro del despliegue cósmico del plan divino: el hombre colaborador de la creación y demiurgo de su evolución, en el descubrimiento, la explotación, la espiritualización de la naturaleza. ${ }^{14}$

Otro aspecto de la interpretación bíblica en Chenu es el recurso a la etimología de algunos términos, que otorga precisión y señala el alcance a sus reflexiones teológicas. Explica que, en el Antiguo Testamento, para referirse al trabajo, existen dos sustantivos que tienen significados diferentes: en primer lugar, al referirse a la obra creadora de Dios, el autor del Génesis usa el término melaka,

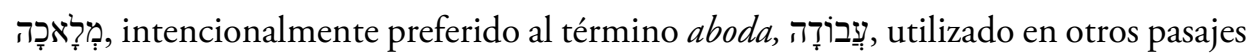
veterotestamentarios. Según Chenu, el que el término trabajo, en el vocabulario del Antiguo Testamento, sea la traducción moderna de dos términos hebreos con significados dispares es ya "significativo":

La palabra melaka, utilizada en Génesis (por ejemplo, en Gn 2,1-3: "Concluyéronse, pues, los cielos y la tierra y todo su aparato, y dio por concluida Dios en el séptimo día la labor que había hecho, y cesó en el día séptimo de toda labor que hiciera. Y bendijo Dios el día séptimo y lo santificó; porque en él cesó Dios de toda la obra creadora que Dios había hecho") ${ }^{15}$ designa la obra creadora de Dios, describe su presencia en la historia y la prosecución de su obra creadora iniciada el primer día. En cambio, aboda significa el trabajo del esclavo, la esclavitud; por ejemplo, el servicio de esclavos bajo Nabucodonosor. En el significado de esos términos se pone de manifiesto la ambigüedad del trabajo: coacción despiadada y plenitud llena de alegría, necesidad implacable y autonomía liberadora. ${ }^{16}$

\footnotetext{
${ }^{14}$ Chenu, El Evangelio en el tiempo, 147-148.

${ }^{15}$ Traducción tomada de la Biblia de Jerusalén (Bilbao: Desclée de Brouwer, 1975).

${ }^{16}$ Chenu, "Trabajo" VI, 674.
} 
Son dos realidades que a partir del texto sagrado ilustran dos lecturas diversas del trabajo, como alienación o como encarnación. Por lo anterior, dada la ambivalencia de la voz "trabajo" al traducir el original hebreo a las lenguas modernas, debe mirarse con cuidado su uso en los diferentes textos bíblicos. Escribe en este sentido Chenu:

Así, según los acontecimientos y las ocasiones, según los temperamentos de los escritores, los libros del Antiguo Testamento ofrecen los juicios más dispares sobre el trabajo. Es imposible sacar de ahí una teoría abstracta del trabajo. Una teología bíblica del trabajo deberá tener en cuenta esta situación en la vida y el matiz de las afirmaciones, y habrá de delimitar entre sí los estadios de reflexión. Trabajo significa algo diferente en cada caso: en los pueblos nómadas, en las ciudades, en la legislación sobre la esclavitud, en la descripción de las grandes empresas constructoras de los reyes, en los conjuros de los profetas contra la opresión de los pobres, y finalmente en los aforismos optimistas o desalentados de los sabios. Todo puede extraerse de estos textos, como lo muestra el pensamiento judeo-cristiano en el curso de las épocas. ${ }^{17}$

El Nuevo Testamento enseña, por su parte, el alcance universal de la obra de Cristo, de modo que "el hecho de la encarnación transforma las relaciones del hombre con la naturaleza y con la historia" ${ }^{18}$. A este respecto, los textos del alcance cósmico de la redención obrada por Cristo, que espera su plenitud en el final de los tiempos, iluminan toda teología del trabajo (véase a $R m$ 8,18-22 y 2P 3,13).

A partir de la revelación bíblica, el trabajo del hombre -como continuación de la obra creadora de Dios- deja de ser instrumento de alienación y se convierte en encarnación del espíritu en la materia. Sin embargo, el trabajo así entendido no es divinización del mundo; no sacraliza el mundo y lo profano. Precisamente, el cristianismo contrarrestó las mitologías que daban un carácter de divinidad a los fenómenos naturales. Se trata de desacralizar el mundo para evitar cualquier tinte de superstición en la relación personal del hombre con Dios.

En conclusión, a pesar de la lectura inicial sociológica y filosófica del trabajo, la Sagrada Escritura es -en Chenu- el fundamento de la teología; una teología encarnada deberá ser fiel al dato escriturístico, pero también estará atenta al llamado de los signos de los tiempos en los que la Palabra será fermento nuevo y antiguo.

\section{La encarnación como argumento de conveniencia en Chenu}

La función concienciadora de la historicidad -en Chenu- es consecuencia de su perspectiva teológica, perspectiva que él mismo denomina "argumento de conveniencia".

\footnotetext{
${ }^{17}$ Ibíd., 674.

${ }^{18}$ Ibíd., 675.
} 
Se trata de una verdad revelada a partir de la cual organiza lógicamente todo su edificio teológico. En Chenu, ese argumento de conveniencia es la encarnación.

Al leer las Sagradas Escrituras, él encuentra en la encarnación un principio desde el que logra organizar lógicamente toda su teología. En efecto, el teólogo dispone del dato revelado y explica sus argumentos a posteriori, presentando los distintos pasajes de la historia de la salvación como momentos en los que conviene que todo suceda de esa forma y no de otra distinta. Dios obra de determinada forma en la historia, no porque se vea obligado a actuar solo de ese modo, sino porque es lo que más conviene hacer desde su plan de salvación.

Escribe Chenu, en su opúsculo, ¿es ciencia la teología?

Pertenece a este orden de conveniencia una altísima operación teológica: la opción que escoge el teólogo dentro del grupo arquitectónico adoptado para construir su síntesis, "Suma", como decían en la Edad Media. Si, para elaborar el conjunto del dato revelado dispongo y construyo sus elementos partiendo de la encarnación y luego hago depender de este acto divino todas las otras verdades, habré obtenido, evidentemente, una visión muy distinta de la de Santo Tomás. Este, en efecto, organiza su Suma sobre el esquema neoplatónico de la emanación y del retorno de los seres, donde el hecho histórico de la encarnación es tan solo un medio escogido para realizar en Cristo el retorno hacia Dios". ${ }^{19}$

Como ya se anotó, en la teología de Chenu, la encarnación es el argumento de conveniencia desde donde construye todo su edificio teológico. Este argumento aporta nueva luz a la relación entre lo sagrado y lo profano. La encarnación no es un olvido del mundo natural; al contrario, responde a las expectativas antropológicas, cosmológicas y metafísicas; se acomoda perfectamente a los requerimientos naturales y los perfecciona. De igual modo, Chenu afirma que la gracia eleva la naturaleza humana sin destruirla. "La gracia no 'sacraliza' la naturaleza cristiana, sino que, haciéndola participar de la vida divina, la revierte más sobre sí misma, la hace más conforme a su propia esencia” ${ }^{20}$. Esta es, en este autor, la lógica del cristianismo que lo hace connatural a la historia.

A pesar de las divergencias en cuanto a las bases de los diversos enfoques teológicos, la fe continúa siendo la misma. La perspectiva encarnacionista, que en teología aparece desde la escuela antioquena, hace énfasis en la humanización de Dios que asume todo lo humano menos el pecado. Desde este enfoque, todo el sistema teológico de Chenu organiza los demás aspectos del plan de salvación: creación y redención. La creación es vista como el inicio de la encarnación de Dios, en su obra, que culminará con la encarnación propiamente dicha de su Hijo único. El trabajo

\footnotetext{
${ }^{19}$ Chenu, ¿Es ciencia la teología?, 95.

${ }^{20}$ Ídem, “Consecratio mundi”, 206.
} 
humano será, desde la perspectiva de la encarnación, la colaboración del hombre en la creación continua obrada por Dios.

\section{Despertar de la conciencia histórica en las obras medievalistas de Chenu}

Otro aspecto relevante de la teología en Chenu es su atención a la tradición de la Iglesia, entendida como el espacio vital en el que crece y se profundiza la fe a lo largo de los siglos. Gracias a la tradición, la teología no es un salto del dato bíblico a la realidad contemporánea a los autores. De este modo, tomar conciencia de la historicidad es reconocer el desarrollo de las líneas, de los énfasis y de los conceptos teológicos en el tiempo.

Con el anterior presupuesto, Chenu recurre al estudio de los siglos XII y XIII para entender mejor la historia contemporánea del mundo y de la Iglesia. Sus estudios medievalistas son acogidos con facilidad por la crítica teológica porque se ubican en el terreno del análisis filológico erudito de textos antiguos y no causan las controversias del diálogo con la visión marxista del trabajo. Del siglo XII, en particular, investiga y conceptualiza tres descubrimientos que marcan un renacimiento de las ciencias, que son fundamentales en la comprensión del trabajo y del hombre: los descubrimientos de la naturaleza (Dama natura), de la conciencia y de la historia.

En primer lugar, en el siglo XII se descubre el valor del mundo natural, gracias a una corriente de pensamiento proveniente del Timeo de Platón (360 a. C.), en la que aparecen temáticas propias de la época, como la "dama natura", el "alma del mundo" y el "hombre microcosmos". Dicha filosofía llega a Europa gracias a la relectura de los padres griegos, especialmente Gregorio de Nisa (siglo IV d. C.), Pseudodionisio (siglo V-VI d. C) y Eriugena (siglo IX d. C).

En esta tendencia naturalista, el descubrimiento de la dignidad del trabajo mecánico, contrapuesto a las artes liberales, es puesto de manifiesto, por la sabiduría de los escultores del siglo XII, que ubica en los pórticos de las grandes catedrales -como la de Chartres- las imágenes de trabajadores que comparten nichos de honor con otras imágenes representativas de las artes liberales y de la historia sagrada; logran así que el pueblo canonice los "oficios" al mismo tiempo que las artes liberales ${ }^{21}$. De nuevo encuentra Chenu "revelaciones" -con minúscula- en lugares donde antes nadie ha buscado. La teología en Chenu deberá estar en diálogo continuo con las artes y con las ciencias.

${ }^{21}$ Ídem, El Evangelio en el tiempo, Nota 13, 141. 
En segundo lugar, en el siglo XII se descubre también la conciencia moral. El descubrimiento de la intencionalidad abre un capítulo nuevo en la calificación de los actos humanos y en la misma definición del hombre. De esta forma, al naturalismo de la escuela de Chartres se contrapone el subjetivismo de la antropología abelardiana. Naturalismo y subjetivismo enriquecen la teología del trabajo. Así describe Chenu el rol de Pedro Abelardo ${ }^{22}$ (1079-1142) en la conceptualización de la conciencia moral:

En los fenómenos sísmicos de los años 1120-1160, el descubrimiento del sujeto fue, mediante Abelardo, uno de los epicentros de la gestación de un hombre nuevo. La moral de la intención provocó este shock subversivo, incluido su exceso. Moral de la intención: según la cual el valor de nuestras acciones y el juicio que estas requieren, delante de Dios y delante de los hombres, se regulan no radicalmente sobre los objetos, en sí mismos buenos o malos, tomados a través de estas acciones -un robo, un homicidio, un acto carnal- sino por el consenso interior (consensus / intentio) que les damos a estas. No es el hecho de matar que, en sí, es pecado, sino el injusto consenso precedente al homicidio. Es la voluntad de cometer un acto prohibido lo que constituye el mal. ${ }^{23}$

En el campo jurídico, el descubrimiento de la conciencia también obra un cambio contra la alienación producida por una moral abstracta. A este respecto escribe Chenu:

El siglo XII vio triunfar las críticas siempre más categóricas contra las ordalías. Los duelos judiciarios, las pruebas del fuego o del agua, los exorcismos y los males de ojo: todos "juicios de Dios", que en un sobrenaturalismo sumario obran una alienación de las conciencias con una transferencia sobre la divinidad de los discernimientos y de las pruebas de la inocencia o de la culpabilidad. ${ }^{24}$

El descubrimiento de la conciencia desde Abelardo marcará la teología, la filosofía y la misma historia. La toma de conciencia será la clave contra la alienación producida por el objetivismo de la moral abstracta en época medieval. En la época contemporánea, la toma de conciencia histórica y social será la clave contra la alienación causada por el maquinismo industrial.

En tercer lugar, el siglo XII es el momento del despertar de la historia. En efecto, escribe Chenu que "no es uno de los méritos menores del siglo XII haber visto nacer, en la cristiandad occidental, una conciencia activa de la historia humana”25.

\footnotetext{
${ }^{22}$ Un estudio completo de la obra de Abelado puede verse en Bonanni, "Parlare della Trinità. Lettura della Theologia Scholarium di Abelardo". En la edición italiana de "Il risveglio della coscienza nella civiltà medievale" de Chenu, aparece también un ensayo sobre la influencia de Abelardo en la teología titulado "L'intelligenza della fede o Abelardo il primo uomo moderno".

${ }^{23}$ Chenu, Il risveglio della coscienza nella civiltà medievale, 25-26.

${ }^{24}$ Ibíd., 31.

${ }^{25}$ Ídem., La teología nel XII secolo, 71.
} 
Contrariamente a la visión unilateral de la antropología de Chartres, que ayudó a cimentar una consideración naturalista del hombre, Chenu encuentra otro tipo de autores del mismo siglo que enfatizaron el aspecto temporal de la existencia humana. Las dos visiones, naturalista e histórica, se complementan y permiten fundamentar teóricamente la teología del trabajo de Chenu.

En el libro La teología en el siglo XII, Chenu relata los principales hitos en la consideración medievalista de la historicidad en teología, comenzando por Hugo de San Víctor, quien "propicia una toma de conciencia del dato cristiano como una serie de eventos en los que es posible percibir valores humanos y divinos de la historia" ${ }^{26}$. Hugo llama a los eventos históricos "series narrationes" en oposición con la conexión lógica que les otorgan las disciplinas teológicas.

Series se refiere a una sucesión organizada, una continuidad articulada cuyas relaciones tienen un sentido, que es efectivamente, el objeto de la inteligibilidad de la historia; no de las ideas platónicas, sino de las iniciativas de Dios en el tiempo de los hombres, de los eventos de la salvación. ${ }^{27}$

Dichas series de acontecimientos evidencian un plan (oıкovo $\mu$ ía o dispensatio) que se va desplegando realmente en la historia.

Gracias a la teología de Hugo de San Víctor y de Anselmo de Havelberg, los eventos no son solo materia de simbolismos inmediatamente alegorizados. Nace de esta forma, en la teología del siglo XII, la conciencia refleja de la historicidad por la que se descubre que los eventos narrados en la Biblia realmente existieron, aunque todavía no se deba hablar de una teología de la historia propiamente dicha. La verdadera historia toma el puesto de la epopeya (cantares de gesta) y las acciones humanas se convierten en objeto de la reflexión teológica. La cristiandad buscará entonces la voluntad de Dios en los eventos, no en las verdades abstractas. No se trata de una curiosidad gratuita sino del deseo de aprender del pasado. ${ }^{28}$

La concatenación y el progreso de los eventos históricos descubren la conciencia de la solidaridad humana, en la obra de la creación y de la redención, la continuidad del tiempo sagrado y profano. Diversamente a la concepción antigua del mito del eterno retorno, los autores cristianos del siglo XII veían la concatenación de los hechos y el progreso de la historia. Se plantea por esta razón que la historia se desarrolla a través de edades, en las que les fue posible "reconducir la cronología pagana a los tiempos sagrados de la Escritura"29.

\footnotetext{
${ }^{26}$ Ibíd., 76.

${ }^{27}$ Ibíd., 76.

${ }^{28}$ Ibíd., 81-82.

${ }^{29}$ Ibíd., 84. En ese sentido, especialmente desde el texto de Dn 7, que menciona una división en edades del tiempo, los autores cristianos de dicho siglo plantean diferentes series de edades categorizadas a partir
} 
Historia, conciencia y mundo natural son, entonces, tres conceptos fundamentales para la teología encarnada, descubiertos en el siglo XII.

\section{Toma de conciencia de la historicidad en el quehacer teológico contemporáneo}

Cuatro siglos después del despertar de la conciencia histórica y natural del siglo XII, la inclusión de la historia como lugar teológico vale el reconocimiento a Melchor Cano (1509-1560) como "fundador de la teología dogmática de la Modernidad, que se caracteriza por la esencial mediación histórica de la Palabra de Dios" ${ }^{30}$.

No obstante, el sentido del concepto historia no es el mismo desde este autor hasta Chenu. En el concepto de historia manejado por Cano, "la luz interior del creyente" no es tomada en consideración en cuanto tal:

...tampoco la experiencia vivida, sino que se trata de proposiciones, operándose de esta manera una separación entre la referencia a los documentos históricos de la tradición, test de la fidelidad objetiva, y el hecho que esta tradición no se reduce a los documentos, sino que incluye la vida de fe guiada por el Espíritu Santo. ${ }^{31}$

En Chenu, la historia como lugar teológico es al contrario el lugar del sensus Ecclesiae que comporta cierta subjetividad. La historia, lugar teológico en el que vive la tradición de la Iglesia, no es solo un repertorio de sus documentos autoritativos y autoritarios. Al contrario, es el espacio en el que -a la luz nueva y antigua de la Palabra, del magisterio, de la liturgia, de los valores cristianos- son examinadas las nuevas problemáticas que enfrenta la comunidad humana en el devenir del tiempo. A pesar del lento desarrollo de la conciencia histórica en la tradición cristiana, esta entra con derecho de ciudadanía -en la teología y el magisterio- solo hasta la segunda mitad del siglo XX.

En efecto, cuatrocientos años después de Cano, se revalida la historia como lugar teológico. El reconocimiento magisterial del estatuto histórico del cristianismo, la atención a las problemáticas contemporáneas, se logra luego de sesenta años de una controversia teológica iniciada con el Modernismo y cerrada con el Concilio Vaticano II (1962-1965), que marca un cambio de marcha al "adoptar este estatuto como una de las referencias de base de su enseñanza, en el que la experiencia

de un determinado aspecto. Descifrar las sucesivas etapas, categorizando los hechos de la revelación bíblica y de la historia universal es una tarea asumida por autores como Otón de Frisinga, Hugo y Ricardo de San Víctor y Anselmo de Havelberg.

${ }^{30}$ Eckholt, La Iglesia en la diversidad, 10.

${ }^{31}$ Chenu, "Le lieux théologiques chez Melchior Cano", 47. 
cristiana ha reencontrado una dimensión dinámica a través del redescubrimiento de la fe" ${ }^{\prime 2}$.

Durante la controversia modernista, el choque entre la revisión histórico-crítica de los textos bíblicos y de los dogmas de fe, promovida por autores como Loissy, Tyrrel y Bonaiuti, en el primer decenio del siglo XX, y la apologética católica de una teología escolástica barroca desenmascara una visión de Iglesia que domina entonces, alejada de los problemas del mundo y de la historia.

Pío X responde al modernismo en teología en 1907 con el decreto Lamentabili y la encíclica Pascendi dominici gregisi3 ${ }^{33}$ condenan el modernismo:

...síntesis de todas las herejías, porque en él confluyen todos los errores del pensamiento moderno: relativismo, subjetivismo, agnosticismo, racionalismo, cientismo, inmanentismo, historicismo, llevando a la resolución de la fe en el sentimiento; del dogma en la historia; de la Iglesia en una sociedad mística. ${ }^{34}$

Sin embargo, el verdadero problema de esta controversia de finales del siglo XIX y la primera mitad del siglo XX es el menosprecio por la historia por parte de la teología y del magisterio de la época.

No fue entonces la utilización del método histórico crítico dentro del conocimiento racional del cristianismo lo que estuvo en juego, sino la actitud de la Iglesia respecto de la historia en tanto que dimensión constitutiva de la condición humana, en tanto que movilidad de la vida individual y social, en tanto que estatuto de la creación. ${ }^{35}$

La progresiva toma de conciencia de la centralidad de la historia en la fe y en la teología va madurando a lo largo de momentos claramente definidos, a saber: la controversia modernista y las condenas magisteriales de inicio de siglo; la controversia posmodernista de la Nouvelle théologie nacida en Le Saulchoir, escuela teológica dominicana francesa a la que responde negativamente la encíclica Humani géneris de Pío XII (1950); y finalmente, el Concilio Vaticano II, que revalida la conciencia histórica al afrontar un diálogo abierto con el mundo contemporáneo.

\footnotetext{
${ }^{32}$ Alberigo, "Christianisme en tant qu'histoire et 'théologie confesante", 26.

${ }^{33}$ Describe el Pontífice el error de los modernistas: "Distinguen con cuidado estas dos historias, y adviértase bien cómo oponen la historia de la fe a la historia real en cuanto real. De donde se sigue que, como ya dijimos, hay dos Cristos: uno, el real, y otro, el que nunca existió de verdad y que solo pertenece a la fe; el uno, que vivió en determinado lugar y época, y el otro, que solo se encuentra en las piadosas especulaciones de la fe. Tal, por ejemplo, es el Cristo que presenta el Evangelio de San Juan, libro que no es, en todo su contenido, sino una mera especulación" (Pio X, "Carta encíclica Pascendi sobre las doctrinas de los modernistas", 29).

${ }^{34}$ Mondin, Storia della teología, 4, 261-262.

${ }^{35}$ Alberigo, "Christianisme en tant qu'histoire et 'théologie confesante”, 28.
} 
En ese recorrido histórico, un acontecimiento central es la condena del Santo Oficio, en 1942, a una obra de Chenu titulada Le Saulchoir, une école de Théologie (1937). Dicho documento, brochure de la escuela, que originalmente no se pretendía publicar, es fácilmente relacionable con el modernismo por su interés en la historia. En efecto, Le Saulchoir fue un centro de reflexión, de investigación teológica e histórica, fiel a la inspiración tomista, pero igualmente comprometido en los problemas que plantea a los cristianos el mundo contemporáneo"36.

No obstante su cercanía al modernismo, la teología de Le Saulchoir se diferencia radicalmente por su acatamiento al magisterio de la Iglesia. Al respecto Chenu comenta: "[Para los modernistas] es la fe -no el dogma- la que es un absoluto, y escapa a la historia, la fe pura en su luz infusa, y no el dogma, auditus fidei, dócil al magisterio" ${ }^{37}$. Sin duda -escribe Chenu-, esta opinión de los modernistas significa "abrir la puerta al relativismo de las fórmulas dogmáticas; pero este relativismo histórico no es sino el efecto, según la sucesión del tiempo, del relativismo metafísico, expresión del conocimiento analógico" 38 .

En definitiva, sostiene Chenu, "el historiador de las doctrinas cristianas -apartado del magisterio- encuentra en la tesis de la inteligibilidad progresiva del dato revelado, con la legitimidad de su trabajo y de su método, la razón de sus observaciones históricas" ${ }^{39}$.

Una observación fundamental distingue a Chenu y a Le Saulchoir del modernismo, y es la consideración de que, a pesar de la historicidad, la fe permanece idéntica. Aquí se distingue la perspectiva del historiador de los dogmas y del teólogo: "Tal es la historia de las doctrinas cristianas, lo que será para el teólogo la materia de la tradición" ${ }^{\prime \prime}$. Chenu adhiere al dato revelado sin reparos: Escritura, tradición y magisterio, que distinguen la teología cristiana propiamente dicha. En ese sentido escribe:

Al tomar en su realidad histórica y espiritual la vida de la Iglesia, como lugar de la tradición, reencontramos el primado del dato en la estructura de la teología, del que ya hemos hablado. Del mismo modo que la Escritura no es más una suerte de "prueba" exterior para la verdad de tal o tal dogma, también la tradición: es para ella misma su propia verdad. Ella es prueba en el sentido que es conciencia cristiana permanente dentro de la Iglesia y sirve de criterio

\footnotetext{
${ }^{36}$ Ibíd., 12.

${ }^{37}$ Chenu, "Une école de théologie: Le Saulchoir", 140.

${ }^{38}$ Ibíd., 140.

${ }^{39}$ Ibíd., 140.

${ }^{40}$ Ibíd., 141.
} 
para juzgar toda innovación. No solamente un quantum de credenda, según una concepción empírica y estática de los loci, sino presencia del Espíritu en el cuerpo social de la Iglesia, divina y humana en el Cristo. No solo conservación de dogmas elaborados, de resultados adquiridos o de decisiones tomadas en el pasado; sino principio creador de inteligibilidad y fuente inagotable de vida nueva. La tradición no es un agregado de tradiciones, sino un principio de continuidad orgánica, del que el magisterio es instrumento infalible, dentro de la realidad teándrica de la Iglesia cuerpo místico de Cristo. ${ }^{41}$

Chenu se mueve dentro de las coordenadas de una teología católica fiel a las enseñanzas del magisterio anterior al Vaticano II y posterior a las definiciones dogmáticas de la infalibilidad papal de 1870 . Por otra parte, reconoce la historicidad propia del ser humano y de la encarnación. El principio que mantiene unido todo su edificio teológico es el primado del dato revelado.

La tradición es, en sus términos, la conciencia viva de la historicidad de la Iglesia: una afirmación que explica cómo la "conciencia de la historicidad en teología" no significa crítica histórica separada de la tradición, sino el reconocimiento de la riqueza de la encarnación realizada progresivamente en la historia, incluso en la sociedad actual. La tradición es, en Chenu, la conciencia histórica en la Iglesia en la que están los datos positivos de la Escritura, el magisterio, la liturgia, etc.

De esta forma, Chenu toma distancia de los autores modernistas de inicio del siglo, quienes confunden historicidad de la fe con historicismo y se autoinvisten de una supuesta autoridad por encima de la tradición y del magisterio. Por el contrario, Chenu afirma:

...ser presente a su tiempo, teológicamente hablando, es ser presente al dato revelado dentro de la vida de la Iglesia y la experiencia actual de la cristiandad. Ahora bien, la tradición es, en la fe, la presencia misma de la revelación. El teólogo vive de esto: sus ojos se abren sobre la cristiandad en trabajo. ${ }^{42}$

La conciencia de la historicidad no significa, entonces, adentrarse en los problemas actuales del mundo escapando a la rica sabiduría cristiana, sino saber leer los "signos de los tiempos" teniendo en cuenta el bagaje de la tradición y el aporte de las ciencias y de las artes.

Entre las realidades contemporáneas que interesan a la teología, en 1937, Chenu menciona las siguientes: el pluralismo de las civilizaciones humanas, las riquezas originales de Oriente, el movimiento ecuménico, la participación de los laicos en la Iglesia,

\footnotetext{
${ }^{41}$ Ibíd., 141.

${ }^{42}$ Ibíd., 142.
} 
la toma de conciencia social y el mundo del trabajo ${ }^{43}$, realidades estas que marcarían el desarrollo posterior del Concilio Vaticano II.

Dicho Concilio representa -en palabras de Chenu- una "toma de conciencia de la Iglesia" que abre nuevas perspectivas al trabajo particular de los teólogos:

Hoy, es la posición misma de la Iglesia de cara al mundo y a sus problemas que es nueva. La Iglesia toma conciencia de ella misma, una conciencia evangélica, y no solamente sociológica, en dejarse interpelar por el mundo, en experimentar ella misma existir en el mundo. ${ }^{44}$

El Concilio Vaticano II restaura la conciencia de la historia por la que luchó y sufrió el padre Chenu. Como destaca M. Faggioli, "la inclusión de la 'historicidad' es uno de los elementos más importantes de la nueva conciencia del Vaticano II" ${ }^{45}$.

\section{Conclusión}

En su teología del trabajo, Chenu -el teólogo de los signos de los tiempos, de la encarnación y de la conciencia de la historicidad- hace del trabajo industrializado un laboratorio: en él se puede evidenciar el desarrollo de la enseñanza ${ }^{46}$ social de la Iglesia en la Escritura y el magisterio, la tradición de los padres griegos y la escuela de Chartres, y el aporte de la filosofía personalista y marxista; igualmente, se puede

\footnotetext{
${ }^{43}$ Ibíd., 142.

${ }^{44}$ Ídem, "Les événements et le royaume de Dieu”, 18.

${ }^{45}$ Faggioli, Vatican II and the Church of the Margins, 810.

${ }^{46}$ Chenu refiere que los padres conciliares, en el Vaticano II, prefirieron expresamente el término "enseñanza" al de "doctrina”, aunque el magisterio posterior lo haya retomado. Menciona una "eliminación del término doctrina, primero implícita y luego intencional, en la época del Concilio: todavía frecuente en Mater et magistra (1961), desaparece en Pacem in Terris (1961) y es excluida de la constitución conciliar Gaudium et spes, donde se sustituye por una fórmula aparentemente semejante en su materialidad, pero diferente en su significación: "Enseñanza social del Evangelio", en lugar de "doctrina", y hace referencia directa al "Evangelio y a su inspiración" (Chenu, La doctrine sociale de l'Église comme idéologie, 87-88). Así mismo, en el artículo "Historicidad e inmutabilidad del ser cristiano", escribe Chenu: "Cuando se habla de 'doctrina social' de la Iglesia, es oportuno aclarar la ambigüedad enojosa de esta expresión". Y lo explica citando a P. Guissard: "No se trata de colocar la doctrina social de la Iglesia en el rango de las doctrinas, en el sentido estricto de la palabra, que se presentan como un conjunto de argumentos teóricos, que dan origen a estructuras precisas y técnicamente organizadas para la instauración de un régimen económico y social que fuera distinto de cualquier otro. No se trata de proponer una 'maqueta cristiana' (K. Rahner), que no estaría exenta de una buena dosis de esquemas condicionados a una época, como de hecho ocurrió, continuamente desde León XIII a Pío XII, y convertiría el mensaje evangélico en una 'ideología', en concurrencia con otras de distinto modelo. En cambio, el carácter concreto de la moral evangélica se acopla a sistemas socio-económicos diversificados" (Chenu, "Historicidad e inmutabilidad del ser cristiano", 163).
} 
evidenciar la voz de quienes anteriormente eran acallados en la sociedad: los pobres, los esclavos alienados por la máquina.

Este artículo testimonia el camino recorrido por el padre Chenu en medio de incomprensiones y persecuciones, que aún hoy llevan a algunos críticos a considerarlo exclusivamente como un excelente medievalista y a restar importancia a su atención por los problemas contemporáneos ${ }^{47}$. Esta es una visión parcial de su obra, que limita sus logros solo en la mente de quienes distinguen despectivamente entre el primer y el segundo Chenu:

Aquel caracterizado por el "objeto" medieval y aquel caracterizado por el "objeto", por así decir, de la actualidad, en el significado de mundo, realidad terrestre, situación eclesial. Según la imagen usada por el mismo Chenu, encontramos los "dos Chenu", si es que existen efectivamente dos, como no parece. Si al caso, la cuestión sería otra, y tendría que ver con el grado de rigor en la aplicación del método histórico en las diversas áreas ocupadas por el interés de Chenu. ${ }^{48}$

La presente investigación teológica sobre la obra de Chenu ha pretendido mostrar la unidad de su pensamiento al revisar intencionalmente sus escritos sobre la teología del trabajo y aquellos sobre el siglo XII desde el concepto de la toma de conciencia de la historicidad.

\section{Bibliografía}

Alberigo, Giuseppe. "Christianisme en tant qu'histoire et 'théologie confesante". En Une école de théologie: Le Saulchoir, editado por G. Alberigo, 11-35. Paris: Du Cerf, 1985.

Biffi, Inos. "Marie-Dominique Chenu (1895-1990)". Credere oggi. Edizioni Messagero di Padova, http://www.credereoggi.it/upload/2003/articolo134_59.asp (consultado el 21 de julo de 2012).

. "Presenza e influsso di M.-D. Chenu in Italia". RSPT 75 (1991): 469-489.

Bonanni, Sergio Paolo. "Parlare della Trinità. Lettura della Theologia Scholarium di Abelardo”. Tesis de Doctorado, Pontificia Università Gregoriana, Roma, 1996.

Chenu, Marie-Dominique. "Consecratio mundi". Nouvelle Revue Théologique 86 (1964): 608-618. Disponible en: Selecciones de teología, http://www.

\footnotetext{
${ }^{47}$ Una cronología completa de la vida y obra de Chenu hasta 1963 se encuentra en la edición española de Chenu, El Evangelio en el tiempo, 659-668.

${ }^{48}$ Biffi, "Presenza e influsso di M.-D. Chenu in Italia", 469.
} 
seleccionesdeteologia.net/selecciones/llib/vol5/19/019_chenu.pdf (consultado el 10 de febrero de 2014).

. El Evangelio en el tiempo. Barcelona: Estela, S. A., 1966.

. ¿Es ciencia la teología? Andorra: Casal i Vall, 1959.

. Hacia una teología del trabajo. Barcelona: Estela, S. A., 1960.

. "Historicidad e inmutabilidad del ser cristiano". En El ateísmo contemporáneo,

Vol. 4, dirigido por G. Girardi, 151-166. Madrid: Cristiandad, 1971.

. Il risveglio della coscienza nella civiltà medievale. Milano: Jaca Book, 1991.

. La doctrine sociale de l'Église comme idéologie. Paris: Du Cerf, 1979.

. La fe en la inteligencia. Bibliografía general de padre Chenu 1922-1965. Barcelona: Estela, 1966.

. "La teología del trabajo frente al ateísmo". En El ateísmo contemporáneo, Vol 4, dirigido por G. Girardi, 295-309. Madrid: Cristiandad, 1971.

. La teología nel XII secolo. Milano: Jaca Book, 1999.

. "Le lieux théologiques chez Melchior Cano". En Le point théologique. Le déplacement de la théologie. En actes du Colloque Méthodologique de février 1976, editado por Institute Catholique, 45-50. Paris: Beauchesne, 1977.

. "Les événements et le royaume de Dieu". ICI 250 (1965): 18-19.

. "Les signes des temps". NRT 97 (1965): 29-39. Disponible en: Selecciones de teología, http://www.seleccionesdeteologia.net/selecciones/lib/vol4/16/016_ chenu.pdf (consultado el 10 de febrero de 2014).

. "L'inteligenza della fede o Abelardo, il primo uomo moderno". En Il risveglio della coscienza nella civiltà medievale, por M-D. Chenu, 69-86. Milano: Jaca Book, 1991.

. "Trabajo”. En Sacramentum Mundi VI, 672-684. Barcelona: Herder, 1975.

. "Une école de théologie: Le Saulchoir". En Une école de théologie: Le Saulchoir, editado por G. Alberigo, 93-176. Paris: Du Cerf, 1985.

Duval, André. "Bibliographie du P. Marie-Dominique Chenu (1921-1965)”. En Mélanges offerts à M.D. Chenu Maître en Théologie, 9-29. Bibliotèque Thomiste 37. Paris: J. Vrin, 1967.

Eckholt, Margit. La Iglesia en la diversidad. Santiago de Chile: Ediciones Universidad Alberto Hurtado, 2007. 
Faggioli, Massimo. "Vatican II and the Church of the Margins". Theological Studies 74 (2013): 808-818.

Gallo, Luis Antonio. La concepción de la salvación y sus presupuestos en Marie-Dominique Chenu. Biblioteca di Scienze Religiose 18. Roma : Librería Ateneo Salesiano, 1977.

Maritain, Jacques. Les droits de l'homme et la loi naturelle. Paris: Éditions de la Maison Française Inc., 1945.

Marx, Karl. Cuadernos de Paris. (Notas de lectura de 1844). México: ERA, 1974. . Manuscritos de economía y filosofía. Madrid: Alianza, 1979.

Mazzarello, María Luisa. “Gli scritti del p. Marie-Dominique Chenu 1963-1979”. Salesianum 42 (1980): 855-866.

Mondin, Battista. Storia della teología. Vol. 4. Bologna: ESD, 1997.

Pablo VI. "Alocución del 10 de mayo de 1964. L’Osservatore romano, Roma, 2 de mayo de 1964.

Pio X. "Carta encíclica Pascendi sobre las doctrinas de los modernistas (1907)". Vatican, http://w2.vatican.va/content/pius-x/es/encyclicals/documents/hf_p-x_ enc_19070908_pascendi-dominici-gregis.html (consultado el 9 de mayo 2016).

Rosanvallon, Pierre. La nouvelle question sociale. Repenser l'Etat-providence. Paris: Du Seuil, 1995.

Schmitt, Jean-Claude. "L'œuvre de médiéviste du père Chenu". RSPT 81 (1997): 397-398. 
